\title{
The effect of climate change on building heating and cooling energy demand in China
}

\author{
Lujian Bai ${ }^{1,2, *}$, Bing Song ${ }^{1}$ \\ ${ }^{1}$ College of Architecture, Xi' an University of Architecture and Technology, 710043 Xi'an, China \\ ${ }^{2}$ College of architecture \&civil engineering, Xi' an University of Science and Technology, 710054 Xi'an, China
}

\begin{abstract}
Climate has a key impact on building energy efficiency. The impact of climate change on heating and cooling degree-days of China during the past 60 years was studied in this paper. The meteorological data of 613 cities published by National Climate Center of China was applied in this research. The study results showed that the impact of climate change on the spatial distribution characteristics of heating and cooling degree-days is obvious. The area with HDD $18{ }^{\circ} \mathrm{C}$ over $2000 \mathrm{~d} \cdot{ }^{\circ} \mathrm{C}$ has dramatic shrunk during recent 30 years compared with the period from 1964 to 1983 , while the area with $\mathrm{CDD} 26{ }^{\circ} \mathrm{C}$ over $90 \mathrm{~d} \cdot{ }^{\circ} \mathrm{C}$ has expanded during recent 30 years. The impact of climate change on the HDD18 ${ }^{\circ} \mathrm{C}$ and CDD2 $6{ }^{\circ} \mathrm{C}$ of each city is inhomogeneity. The decrease of HDD $18{ }^{\circ} \mathrm{C}$ mainly occurred in the north and northwest of China, and the increase of CDD26 mainly occurred in the southeast of China. The outcomes of this paper may provide a theoretical basis for building energy efficiency design in future.
\end{abstract}

\section{Introduction}

Climate change has aroused much concern around the world in recent years. The fifth assessment report by Intergovernmental Panel on Climate Change (IPCC) indicated that the total increase between the average of the $1850-1900$ period and the $2003-2012$ period is $0.78{ }^{\circ} \mathrm{C}$ [1]. Climate change not only has significant effect on natural environment and human settlement, but also has a decisive impact on building energy consumption and building energy efficiency design. Plentiful study results indicated that climate change will have a distinct impact on building energy consumption in future [2-6]. Therefore, a better understanding of the trend of building heating and cooling energy demand under the current context of climate change is crucial for implementing adequate technical measures and energy policies to alleviate the impact of climate change and achieving building energysaving.

Degree days is an important climatic indicator and a simplest method for building energy analysis and forecast [7]. Since degree days can precisely represent the regional climate characteristic related to building energy consumption, it was applied to classify building climate zones in many countries and assess the impact of climate change on buildings. McGilligan developed a new index based on adaptive thermal comfort model, named adaptive comfort degree-days, to analysing the impact of climate warming on building energy consumption and found that the carbon emissions must decrease if society is not to suffer the more extreme [8]. OrtizBeviá investigated the evolution of heating and cooling degree-days in the Spain according to the present and future climate data, and the analysis results showed that the cooling degree-days have increased 50\% compared with their values in the historical period [9]. Frank studied the impact of climate change on office and residential building heating and cooling energy demand by using the hourly weather data scenarios for the Zurich-Kloten location, and indicated that the annual heating energy demand of residential buildings would decrease $33-44 \%$ during the period $2050-2100$, and the annual cooling energy demand of office buildings would increase 223-1050\% during the same period [10]. According to the plentiful research results, the trend of cooling degree-days and heating degree-days suggested that the efficient solar protection and passive cooling strategies should be paid more attention in future to keep indoor air temperature within the comfortable level. Moreover, Christenson and Dombayc found that the decrease of heating degree-days and the increase of cooling degree-days depended on the threshold temperature and location, and the current weather data used for building design would lead to overestimate heating demand and underestimate cooling demand [11,12].

In China, the climate change shows a considerable similarity with the global. The average annual mean surface air temperature increased $1.1{ }^{\circ} \mathrm{C}$ during the past 50 years and it increased $0.8{ }^{\circ} \mathrm{C}$ during the past 100 years [13]. However, only a few researches discussed the effect of climate change on case building energy consumption and indoor thermal environment. The impact of climate change during the past 60 years on heating and cooling degree-days of China is still obscure. To resolve this problem, the object of this study is to analyze the historical

${ }^{*}$ Corresponding author: bailujian@xust.edu.cn 
trends of degree days in China, both for heating and cooling, and the impact of these trends on building energy demand in future.

\section{Method}

\subsection{Degree-days calculation methods}

Degree-days can be classified to monthly degree-days, annual degree-days and daily degree-days. In this study, the heating and cooling degree-days refers to daily degreedays. Heating degree-days (HDD) is defined as the negative deviation of daily outdoor air temperature ( $\mathrm{t}$ - o ) from the base temperature $\left(t \_b\right)$ in a year, which means that the heating is needed to keep indoor air temperature within the comfortable level when the outdoor air temperature is below the base temperature. Likewise, Cooling degree-days (CDD) is defined as the positive deviation of daily outdoor air temperature from the base temperature in a year, which means that the cooling is needed to keep indoor air temperature at a rational level. The equation of heating and cooling degree-days can be written as following.

$$
\begin{aligned}
& H D D=(1 \text { day }) \sum_{\text {daus }}\left(t_{b}-t_{o}\right)^{+} \\
& C D D=(1 \text { day }) \sum_{\text {daus }}\left(t_{o}-t_{b}\right)^{+}
\end{aligned}
$$

In this study, the base temperature is determined according to the code for thermal design of civil building (GB 50176-2016) [14]. The base temperature of heating degree-days and cooling degree-days is $18{ }^{\circ} \mathrm{C}$ and $26^{\circ} \mathrm{C}$, respectively.

\subsection{The resource of weather data}

The meteorological data applied in this study is derived from a daily database developed by the National Climate Center of China. Totally 613 cities, measured from 1964 to 2013, were selected from the database for this study. The daily average value of each meteorological element in this database was calculated by employing the arithmetic mean method with recorded values measured 4 times each day.

\section{Results and analysis}

As shown in Fig. 1 and Fig. 2, the spatial distribution characteristics of heating and cooling degree-days during the period from 1964 to 1983 and from 1984 to 2013 were presented by ArcGIS software. The inverse distance weight method was applied to analyze the spatial distribution characteristics of heating and cooling degreedays. The heating degree-days with high value is mainly concentrate in the northeast and southeast referring primarily to Qinghai-Tibet Plateau of China. It suggests that the heating demand is dominated and strict thermal insulation of building exterior envelope is needed during the cold season. On the other side, the heating degree-days is decreasing with the increase of the latitude in the southeast of China. Although the general spatial distribution characteristics in these two different periods is similar, the impact of climate change on heating degreedays is obvious. The maximum value of heating degreedays decreases from $8657 \mathrm{~d}^{\circ} \mathrm{C}$ (with climate date from 1964 to 1983 ) to $8341 \mathrm{~d} \cdot{ }^{\circ} \mathrm{C}$ (with climate date from 1984 to 2013). The area with high heating degree-days over $2000 \mathrm{~d} \cdot{ }^{\circ} \mathrm{C}$ has dramatic shrunk during recent 30 years compared with the period from 1964 to 1983, and this trend have specifically presented in Fig. 2 . It can be found that the lines of $\operatorname{HDD} 18^{\circ} \mathrm{C}$ valued $3800 \mathrm{~d} \cdot{ }^{\circ} \mathrm{C}$ and $2000 \mathrm{~d} \cdot{ }^{\circ} \mathrm{C}$ respectively have shifted towards north in eastern China. According to the code for thermal design of civil building (GB 50176-2016) [14], the line of HDD $18^{\circ} \mathrm{C}$ valued 2000 $\mathrm{d} \cdot{ }^{\circ} \mathrm{C}$ corresponds to the boundary between the cold zone and hot summer and cold winter zone. To reduce heat loss and heating energy consumption is the primary goal for building energy efficiency design in the cold zone, while to prevent overheating and lower cooling energy consumption is the primary goal in the hot summer and cold winter zone. Due to the change of the boundaries between these two zones, the building design strategy and exterior envelope design requirements of cities located in the changed regions may need to be adjusted.

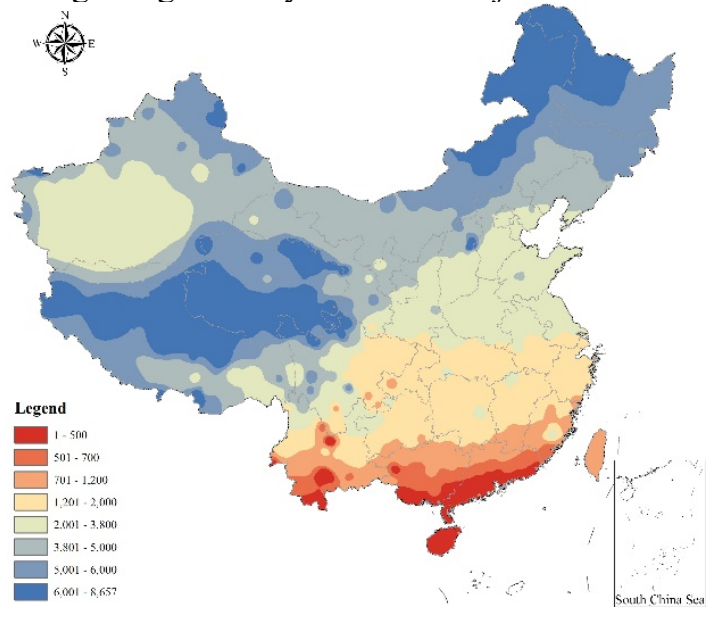

(a) $1964 \sim 1983$

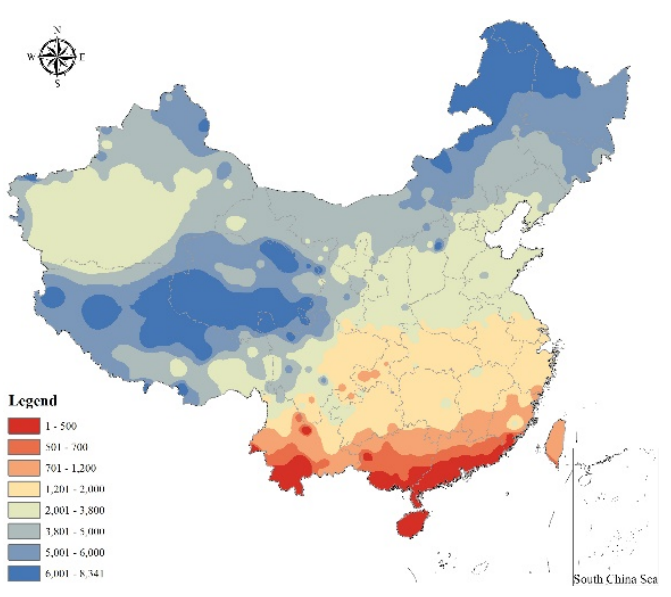

(b) $1984-2013$

Fig1. The Spatial distribution characteristics of HDD $18{ }^{\circ} \mathrm{C}$ during different periods. 


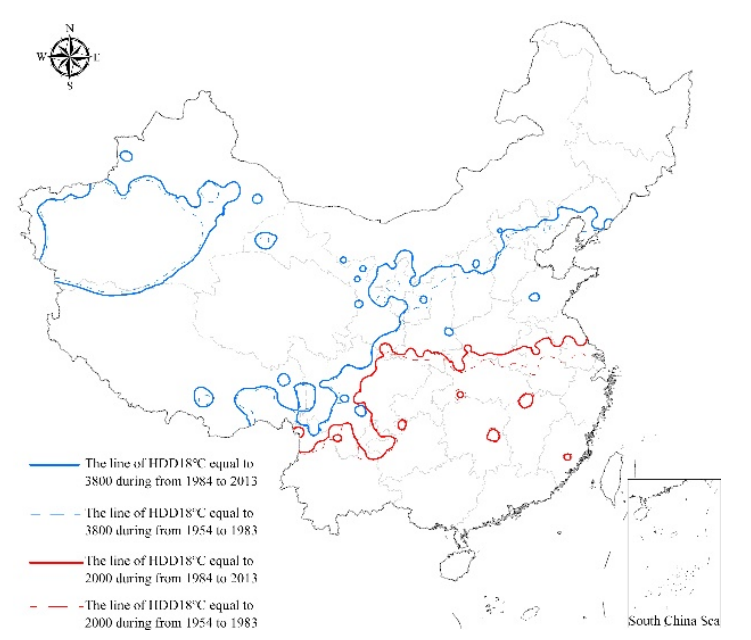

Fig2. The variation of boundary of HDD $18^{\circ} \mathrm{C}$ during different periods.

Based on the code for thermal design of civil building (GB 50176-2016), building design strategies to prevent overheating should be considered when its $\mathrm{CDD} 26{ }^{\circ} \mathrm{C}$ is over $90 \mathrm{~d} \cdot{ }^{\circ} \mathrm{C}$. As shown in Fig. 3, the region where CDD26 ${ }^{\circ} \mathrm{C}$ over $90 \mathrm{~d} \cdot{ }^{\circ} \mathrm{C}$ mainly concentrates in the northwest and southeast of China. Contrary to $\operatorname{HDD} 18^{\circ} \mathrm{C}$, the maximum value of cooling degree-days increase from $543 \mathrm{~d} \cdot{ }^{\circ} \mathrm{C}$ (with climate date from 1964 to 1983 ) to $584 \mathrm{~d} \cdot{ }^{\circ} \mathrm{C}$ (with climate date from 1984 to 2013). The area with CDD2 $6{ }^{\circ} \mathrm{C}$ over $90 \mathrm{~d} \cdot{ }^{\circ} \mathrm{C}$ has expanded during recent 30 years compared with the period from 1964 to 1983 shown in Fig. 4. It suggests that some cities which do not need to consider shading and other strategies to prevent overheating at first should consider these design strategies now.

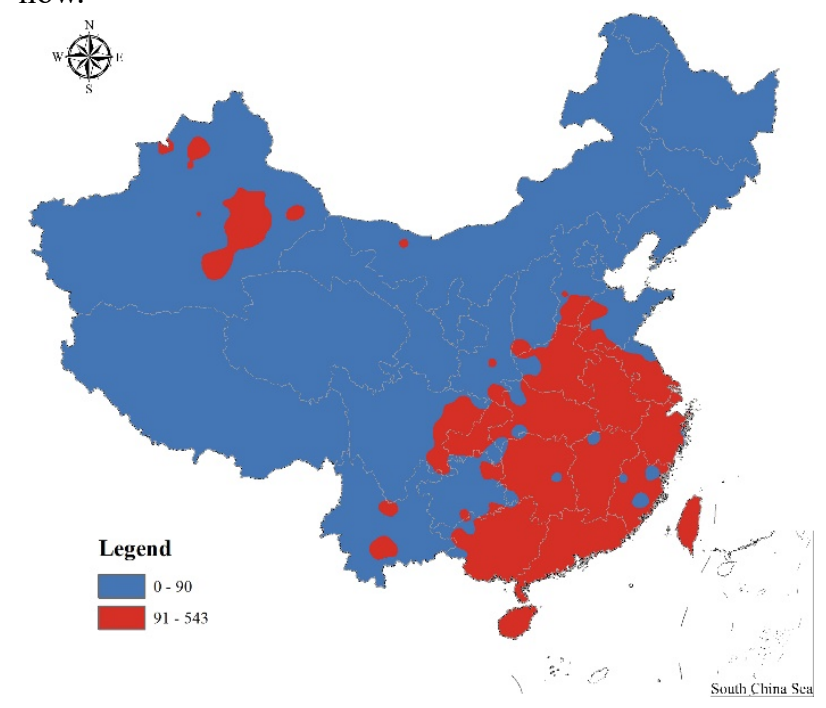

(a) $1964 \sim 1983$

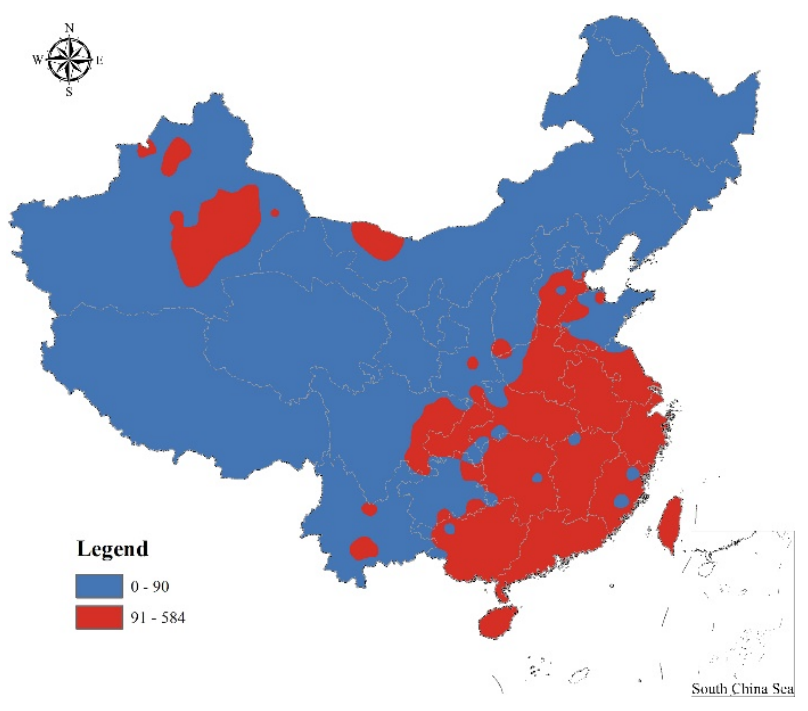

(b) 1984-2013

Fig3. The Spatial distribution characteristics of $\mathrm{CDD} 26{ }^{\circ} \mathrm{C}$ during different period.

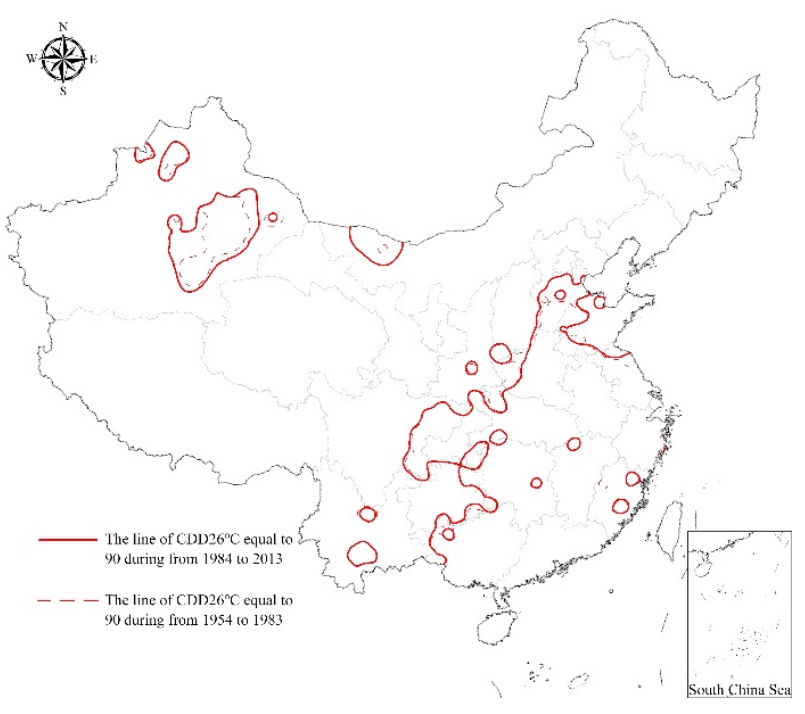

Fig4. The variation of boundary of CDD $26^{\circ} \mathrm{C}$ during different period.

To present the impact of climate change on heating and cooling degree-days in detail, the variation of HDD $18{ }^{\circ} \mathrm{C}$ and CDD2 $6{ }^{\circ} \mathrm{C}$ of each city during different period was shown in Fig. 5. In this figure, the red circle represents the HDD $18{ }^{\circ} \mathrm{C}$ or CDD26 ${ }^{\circ} \mathrm{C}$ respectively increase during recent 30 years compared with the period from 1964 to 1983. The blue circle represents decrease and the green circle represents unchanged. And the size of the circle represents the degree of variation. It can be found that the impact of climate change on the HDD $18{ }^{\circ} \mathrm{C}$ and $\mathrm{CDD} 26^{\circ} \mathrm{C}$ of each city is inhomogeneity. The increase of CDD2 $6{ }^{\circ} \mathrm{C}$ mainly occurred in cities located in the province of Hebei, Xinjiang, Hubei, Zhejiang, Jiangxi, Fujian, Guangdong, Guangxi and Haikou. Unlikely, the decrease of HDD $18^{\circ} \mathrm{C}$ mainly occurred in cities located in the north and northwest of China. 


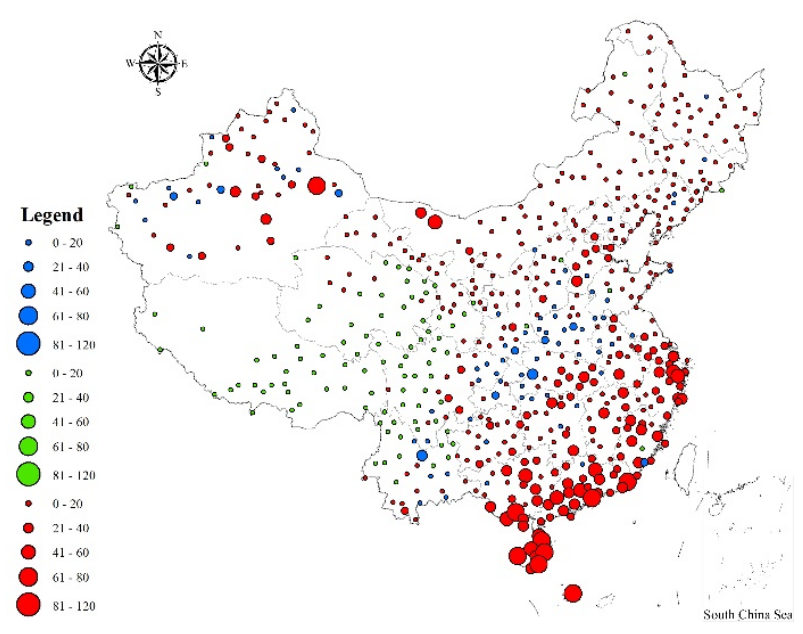

(a) Cooling Degree-days

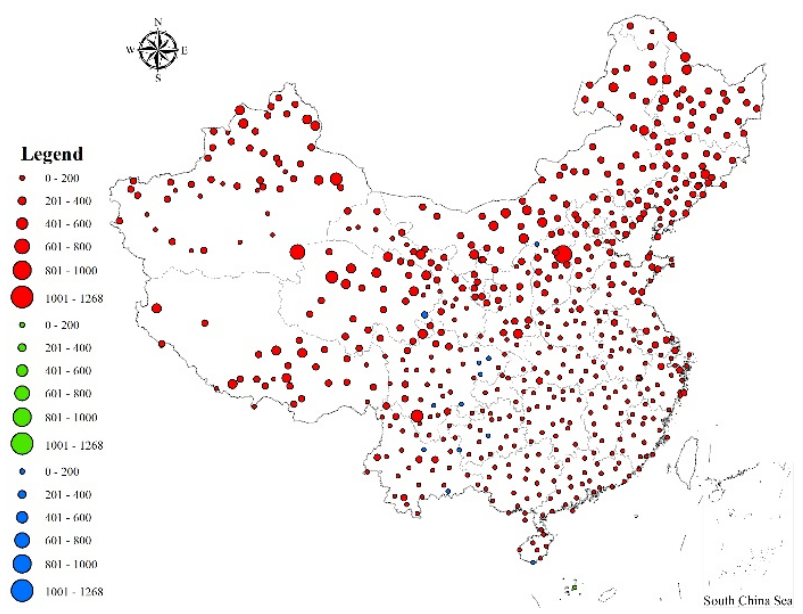

(b) Heating Degree-days

Fig5. The variation of heating and cooling degree-days of each city between different period.

\section{Conclusions}

Design with climate is a basic approach to achieve building energy efficiency. The effect of climate change on building design and energy consumption should be considered. In this paper, the impact of climate change on heating and cooling degree-days in China during the past sixty years was analyzed. It can be found that the area with HDD $18^{\circ} \mathrm{C}$ over $2000 \mathrm{~d}^{\circ} \mathrm{C}$ has dramatic shrunk during recent 30 years compared with the period from 1964 to 1983, while the area with $\mathrm{CDD} 26{ }^{\circ} \mathrm{C}$ over $90 \mathrm{~d} \cdot{ }^{\circ} \mathrm{C}$ has expanded during recent 30 years. The impact of climate change on the HDD $18{ }^{\circ} \mathrm{C}$ and $\mathrm{CDD} 26^{\circ} \mathrm{C}$ of each city is inhomogeneity. The decrease of $\mathrm{HDD} 18{ }^{\circ} \mathrm{C}$ mainly occurred in the north and northwest of China, and the increase of CDD26 mainly occurred in the southeast of China. These variations indicate that the design strategies to prevent overheating should be taken more consideration in future.

\section{References}

1. IPCC, Summary for Policymakers (Cambridge
University Press, Cambridge, 2013)

2. D.H.W. Li, L. Yang, J.C. Lam, Energy 42, 103-112 (2012)

3. K.K.W. Wan, D.H.W. Li, W. Pan, J.C. Lam, Applied Energy 97, 274-282 (2012)

4. M. Li, J. Cao, M. Xiong, J. Li, X. Feng, Energy \& Buildings 173, 38-44 (2018)

5. F. Meng, M. Li, J. Cao, Theoretical and Applied Climatology 133, 521-530 (2017)

6. P. Chinowsky, A. Schweikert, C. Hayles, Procedia Economics and Finance 18, 456-464 (2014)

7. ASHRAE, ASHRAE Handbook: Fundamentals. (ASHRAE Inc., Atlanta, 2013)

8. M. Charles, N. Sukumar, N. Marialena, Energy and Buildings 43, 2767-2778 (2011)

9. M.J. OrtizBeviá, G. Sánchez-López, F.J. AlvarezGarcìa, Global and Planetary Change 92, 236-247 (2012)

10. T. Frank, Energy and Buildings 37, 1175-1185 (2005)

11. M. Christenson, H. Manz, D. Gyalistras, Energy Conversion and Management 47, 671-686 (2006)

12. D. Altan, Energy 34, 1807-1812 (2009)

13. X. Zhang, X. Yan, Theor Appl Climatol 115, 167-175 (2014)

14. MOHURD, The code for thermal design of civil building (GB 50176-2016) (China Architecture \& Building Press, Beijing, 2016) 